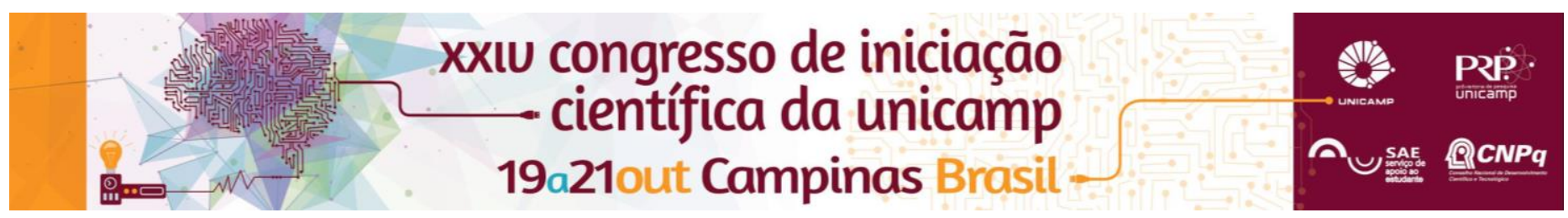

\title{
ATITUDES DOS ENFERMEIROS DE UMA UNIDADE DE TERAPIA INTENSIVA QUANTO AO PROCESSO DE ENFERMAGEM
}

\author{
Beatriz Pera de Almeida*, Flávia de Souza Barbosa Dias, Elenice Valentim Carmona
}

\begin{abstract}
Resumo
Objetivo: descrever as atitudes dos enfermeiros de uma Unidade de Terapia Intensiva de um hospital público de ensino sobre o Processo de Enfermagem. Metodologia: estudo descritivo e transversal. Utilizou-se uma ficha de caracterização da amostra e o instrumento Posições sobre o Processo de Enfermagem (PPE). Resultados e Discussão: 60 enfermeiros; 91,7\% (55) realizam o PE; 58\% (35) utilizam classificações de enfermagem; escore médio PPE: 108,50 $(\mathrm{DP}=19,82)$. Escore mais baixo: item rotineiro/criativo; Escore mais alto: item sem importância/ importante $(6,03)$. A média para a afirmação que os enfermeiros são favoráveis ao PE: 6,42 ( $\mathrm{DP}=0,89)$. Conclusão: os enfermeiros são favoráveis e apresentam atitudes positivas em relação ao PE.
\end{abstract}

\section{Palavras-chave:}

Enfermeiras e Enfermeiros; Cuidados de Enfermagem; Processos de Enfermagem.

\section{Introdução}

O Processo de Enfermagem (PE) é um método de resolução de problemas e um processo de tomada de decisão, que serve como estrutura para o cuidado de enfermagem. Os profissionais que possuem atitudes mais favoráveis ao $\mathrm{PE}$ provavelmente serão aqueles mais envolvidos com a sua implementação. Entende-se atitude como uma posição que leva o profissional a tomar uma decisão e agir de determinada maneira.

Sendo assim, o objetivo geral deste estudo foi descrever as atitudes dos enfermeiros de uma Unidade de Terapia Intensiva (UTI) de um hospital público de ensino sobre o PE.

\section{Resultados e Discussão}

Estudo descritivo e transversal. Utilizou-se o instrumento Posições sobre o Processo de Enfermagem (PPE) e uma ficha de caracterização da amostra para a coleta de dados.

Amostra composta por 60 enfermeiros, $81,67 \%$ (49) do sexo feminino, com média de idade de 39,92 $(\mathrm{DP}=8,94)$ anos, $70 \%$ (42) possui título de especialização e destes $62,22 \%$ (28) atuam na área de especialização. $56,67 \%$ (34) dos enfermeiros relataram possuir atuação prévia como técnico ou auxiliar de enfermagem. 91,7\% (55) referiram realizar o PE, 58,3\% (35) referiram utilizar classificações de enfermagem e 65\% (39) atribuíram o escore máximo à afirmação geral sobre serem favoráveis ao PE. O escore médio para esta afirmação foi de 6,42 $(\mathrm{DP}=0,89)$.

Em relação ao instrumento utilizado, obteve-se escore total médio de 108,5 para a escala de avaliação das atitudes dos enfermeiros, sendo que esta escala possui pontuação variável de 20 a 140 . Item com maior escore médio: sem importância/importante $(6,03)$. Item com menor escore médio: rotineiro/criativo $(3,97)$. A visão do PE como algo rotineiro pode ser advinda da realização de muitas tarefas pelo enfermeiro, o que pode criar uma visão burocrática da realização da SAE.

De acordo com os resultados supracitados, os enfermeiros referem ser favoráveis e apresentam atitudes positivas, o que corrobora com os resultados de outros estudos com a mesma temática. A maioria dos enfermeiros da amostra possui especialização, o que pode ter contribuído para este resultado, uma vez que se DOI: 10.19146/pibic-2016-51522 sabe que o conhecimento ineficiente do trabalho em unidades complexas pode prejudicar a realização da SAE, contrapondo esta constatação.

Pouco contato foi identificado com pesquisa ( média $=2,28$ ), eventos ( édia $=2,32$ ), aulas ( édia $=$ 2,50 ) e leitura (média $=2,83$ ) de literatura com a temática do PE. Estes resultados demonstram a falta de atualização científica dos enfermeiros, o que dificulta a realização da SAE. Além disto, pouco mais da metade dos enfermeiros referiram utilizar classificações de enfermagem, o que também pode ser um reflexo da falta de estudo acerca da temática em questão.

A satisfação dos enfermeiros com a unidade em que atuam $(r=0,26 ; p=0,048)$ e satisfação com a carreira $(r=0,26 ; p=0,048)$ apresentaram fraca correlação positiva com o escore médio da escala de PPE. Não houve correlação significativa com a idade $(r=0,025 ; p=0,847)$ e o tempo de término da graduação $(r=-0,02 ; p=0,855)$ ou valores significativos nas comparações entre o escore médio da escala de PPE e a atuação prévia do enfermeiro como técnico de enfermagem (sim: $n=34$, média=107,68; não: $n=26$, média $=109,58$ ) ou o número de empregos que o enfermeiro possui (1: $n=40$, média $=110,15 ; 2$ ou mais: $n=20$, média $=105,20$ ).

\section{Conclusões}

Os enfermeiros da amostra referem ser favoráveis e apresentam atitudes positivas quanto ao PE, além de o considerarem importante, porém rotineiro. Pouco contato com pesquisas, aulas, eventos e leituras da temática foi identificado. Recomenda-se a promoção de educação continuada e estímulo institucional para que os profissionais participem de eventos científicos com a temática para maior embasamento científico do cuidado e oferta de melhor qualidade de assistência ao paciente.

\footnotetext{
Guedes ES, Turrini RNT, Sousa RMC, Baltar VT, Cruz DALM. Atitudes dos profissionais de enfermagem relacionadas ao Processo de Enfermagem. Rev Esc Enferm USP. 2012; 46(Esp):130-7.
}

Guedes ES, Sousa RMC, Turrini RNT, Baltar VT, Cruz DALM. Adaptação e validação do instrumento Posições sobre o Processo de Enfermagem. Rev LatinoamEnferm (Online); 21(1):[08 telas]. 